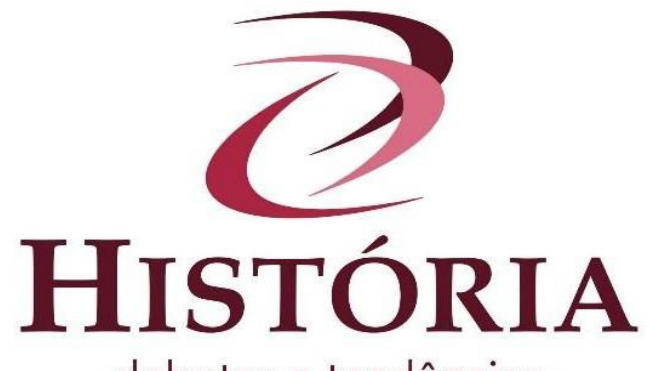

\title{
Cultura, identidade(s) e memória na imigração polonesa no Rio Grande do Sul
}

\author{
Culture, identity(s) and memory in Polish immigration in Rio Grande do Sul
}

\author{
Kultura, tożsamość i pamięć w polskiej imigracji regionu Rio Grande do Sul
}

Thaís Janaina Wenczenovicz ${ }^{\mathrm{i}}$

\begin{abstract}
Resumo: O patrimônio cultural da humanidade é constituído de bens materiais e imateriais que reportam à cultura, à identidade e à memória da sociedade. Estes documentos constituem registros variados, produzidos por uma pessoa, grupos diversificados ou instituição no decorrer de suas atividades. Dessa forma, os registros formam acervos documentais, ou seja, patrimônios documentais que são relevantes para a história e a memória das coletividades e por isso são preservados. O estudo apresenta alguns lugares de guarda e preservação de memórias de Imigrantes Poloneses no Estado do Rio Grande do Sul em espaços múltiplos como Arquivos Pessoais, Arquivos Públicos, Associações, Cartórios, Igrejas e Museus. Enquanto procedimento utiliza-se o bibliográfico-investigativo, acrescido de pesquisa de campo.
\end{abstract}

Palavras-chave: Cultura. Imigrantes poloneses. Memória.

\begin{abstract}
The humanity cultural patrimony is full of material and immaterial things which keep alive the society's culture, identity and memory. These documents are several kinds of records, produced by only one person, different groups or institutions along their activities. On this way, the records are documentary collections, that is, documentary patrimonies that are relevant for the history and the memory of the collectivity, and because of that they are preserved. This study shows some places that keep and preserve Polish Immigrants' memories in the State of Rio Grande do Sul, in multiple spaces like Personal Archive, Public Archive, Associations, Registries, Churches and Museums. It was used bibliography and investigative procedure, plus of field research.
\end{abstract}

Keywords: Culture. Polish immigrants. Memory.

Streszczenie: Dziedzictwo kulturowe ludzkości jest pełne rzeczy materialnych i niematerialnych, które ożywiają kulturę, tożsamość i pamięć społeczeństwa. Niniejszy artykuł skupia się na kwestii ochrony miejsc pamięci imigrantów oraz potomków Polaków w regionu Rio Grande do Sul, w południowej Brazylii. Praca przedstawia przegląd danych dotyczących instytucji oraz miejsc przechowywania informacji i zbiorów o potencjale informacyjnym na temat historii imigracji. Wśród przestrzeni objętych analizą znalazły się archiwa osobiste, archiwa publiczne, stowarzyszenia, rejestry, kościoły i muzea.

Słowa kluczowe: Kultura. Polscy imigranci. Pamięć. 


\section{Introdução}

A relação entre os espaços de memória enquanto materialidade (arquivos, conjuntos documentais e museus) com o tempo presente tem sido motivo para um semnúmero de desafios, discussões e preocupações. Estes implicam reflexão e proposição de alternativas, mudanças de posturas e criação de práticas para a manutenção, renovação e vitalidade destas instituições e, em se tratando de espaços étnicos as reflexões exigem multiplicidade de olhares. Os arquivos, museus e outros espaços emergem como territórios de preservação da memória e sempre em conexão com o seu tempo produtor. Isto implica numa dinâmica de interpretação dualista.

De um lado, os espaços de memória constituem-se como territórios de preservação da memória, cultura material e formas intangíveis do patrimônio cultural, cuja dinâmica do tempo tende, por outro lado, a subsumir da paisagem e do vivido social; por outro lado, assumem-se como sujeitos que podem atribuir valor e importância a estes mesmos elementos, independentemente de sua condição de fragilidade - ou não - no contexto social.

Sob outra ótica, os espaços de memória (Arquivos, Museus etc.) são territórios que sofrem a ação do tempo - envelhecem e, passadas algumas décadas ou mesmo alguns anos de sua fundação/formação, podem se tornar objetos de estranhamento por preservarem uma memória-história não mais reconhecida no presente. Originários de um passado distante, estes territórios da memória tendem a expressar concepções e perspectivas que, potencialmente, podem ser desvalorizadas pelas novas gerações implicando numa série de desafios aos gestores e mantenedores.

Nesse contexto, o estudo apresenta uma pesquisa realizada nos anos de 2016 a 2018 junto aos municípios do Estado do Rio Grande do Sul com a finalidade de apresentar alguns espaços de memória dos imigrantes e descendentes de poloneses chegados ao Brasil nos séculos XIX e XX. Esta experiência - ainda em curso - coloca em discussão duas outras questões que lhe são constitutivas: os condicionantes da produção da memória coletiva e o percurso histórico da criação de uma memória sobre a imigração no país e no Rio Grande do Sul.

O Estado do Rio Grande do Sul possui 497 municípios e está dividido em 11 diferentes regiões fisiográficas que impactaram no processo de ocupação e povoamento do território. Diversas foram as razões que influenciaram no processo de ocupação e povoamento das terras por grupos não originários e dessa forma adentram diversos grupos 
europeus na categoria de imigrantes. Provenientes de diversos países, associados às políticas multifacetadas, homens e mulheres adentraram em terras desconhecidas geralmente para obter melhores condições de vida, seja econômica, política, social ou religiosa.

$\mathrm{O}$ artigo divide-se em duas partes. A primeira traz um breve panorama do processo imigratório de poloneses no Rio Grande do Sul. A segunda apresenta o resultado de uma pesquisa realizada nos municípios do Estado do Rio Grande do Sul que possuem registro de um ou mais espaços de guarda de memória de imigrantes ou descendentes de poloneses. Utiliza-se do procedimento metodológico bibliográfico-investigativo, acrescido de pesquisa realizada em Acervos e Arquivos históricos e etnográficos privados e públicos, associações étnicas, cemitérios, igrejas, prefeituras municipais e sindicatos (modo presencial e digital).

\section{Processos de chegadas e partidas: perspectivas sobre a imigração polonesa no Sul do Brasil}

Apresentar as razões que justificam o deslocamento de milhares de pessoas de um continente para outro não pressupõe uma resposta imediata e simples, e a implicação é ainda maior quando se apresenta a prática cotidiana desses grupos humanos que se deslocaram além-mar, em especial os imigrantes poloneses, como objeto de estudo. Optou-se, neste estudo, por tomar como ponto de partida as condições específicas de imigrantes poloneses, destacando algumas características mais abrangentes, para, posteriormente, adentrar na guarda da memória em si.

As razões da emigração polonesa eram diversas e profundas. No século XIX, à semelhança de outros países europeus, a Polônia vivia grave crise econômica, política e social, o que obrigou milhares de indivíduos a migrar para o Novo Mundo.

Na Polônia era quase inviável tornar-se proprietário de terra, pois nos séculos XVIII e XIX o poder político e econômico estava nas mãos da nobreza. A pequena e média burguesia progredia com dificuldade, enquanto a alta burguesia, ligada à alta nobreza, acelerava o passo, sem questionar a estrutura vigente. Wachowicz (1974, p. 86) relata a respeito: "O camponês polonês, tanto sob o domínio prussiano como sob os outros domínios, vivia num sistema social altamente hierarquizado. Numa aldeia as classes sociais eram nítidas e sua mobilidade muito hierarquizada". Obrigado a arrendar a terra, o camponês cedia grande parte do seu trabalho como renda. 
Nesse contexto que bloqueava a ascensão social dos segmentos subalternos, o camponês era visto e tido como simples força braçal geradora de trabalho. Além disso, seu alheamento a quase tudo que se encontrava situado fora de sua aldeia e arredores okolica, apoiado pela aristocracia e pelo clero, - dificultava-lhe a luta pela divisão da terra e de aplicação de leis agrárias. O historiador brasileiro Ruy Christovam acrescenta:

\footnotetext{
Vivendo pois, numa comunidade semifeudal, possuía oportunidades de pertencer a poucas instituições sociais. A comuna e a paróquia eram o seu mundo. Sua participação na primeira era muito limitada. Medidas restritivas do governo faziam com que sua participação na administração comunal fosse a de espectador passivo [...]. (WACHOWICZ, 1974, p. 86)
}

Também o pequeno proprietário via-se em grandes dificuldades. Stawinski (1976, p. 86) assinala: "Na área econômica, a situação dos poloneses tornara-se ainda mais cruciante. Os impostos prediais e territoriais eram tão pesados que os proprietários não tinham com o que pagar e, para não caírem na prisão, eram forçados a vender suas reduzidas propriedades." Durante dezenas de anos a economia polonesa alicerçou-se na agricultura, com destaque para alguns produtos básicos, como a batata, o centeio e o trigo. A Posnânia e a Pomerânia Ocidental eram bons exemplos desse tipo de economia: tratavase de regiões essencialmente agrícolas, com um número incipiente de indústrias.

Dois grandes períodos caracterizaram os movimentos migratórios poloneses para o Brasil entre a década de 1890 e a I Guerra Mundial, nomeados pela historiografia de "febre brasileira": o primeiro abrange de 1890 até 1897, quando o governo brasileiro proporcionou transporte gratuito aos imigrantes, por meio de contratos com companhias de navegação; o segundo iniciou-se em 1906.

As primeiras levas de poloneses dirigiram-se para o Paraná e o Rio Grande do Sul. São Paulo, Minas Gerais e Espírito Santo também receberam poloneses que se distribuíram pelos centros urbanos e pelas fazendas de café. De 1897 a 1906, caiu bruscamente o número de imigrantes poloneses; chegavam apenas imigrantes isolados, geralmente atraídos por amigos e parentes residentes no Brasil. Wachowicz (1974, p. 55) assim descreve o segundo período:

\footnotetext{
[...] inicia-se por volta de 1906, quando o Brasil, necessitando de mão-de-obra barata e numerosa para a construção de estradas-de-ferro, notadamente a São Paulo - Rio Grande do Sul, volta à sua antiga política de proporcionar passagem gratuita a quem desejasse imigrar."
}

Já Smola apresentam uma periodização mais detalhada das etapas do processo migratório, que divide em sete períodos: “1) até 1869 - início da emigração em massa; 2) 
1869/90 - primeira fase da emigração em massa; 3) 1890/1914 - etapa da febre brasileira; 4) $1914 / 1918 / 20$ - queda da emigração originada pela I Guerra Mundial e os acontecimentos nacionais; 5) 1918/1939 - emigração dirigida, relacionada com ações do Estado polonês; 6) 1939/1945 - etapa dos refugiados de guerra; 7) 1945 - etapa contemporânea." (SMOLA; DEMBICZ, 1996, p. 23).

É importante ressaltar a dificuldade em se apresentar estatísticas quanto ao número de imigrantes egressos da Polônia, visto que em grande parte das fontes estatísticas são elencados na categoria "outras nacionalidades" por questões essencialmente econômicas e políticas vivenciadas pela Polônia (partilhas, guerras, dentre outras). A categoria que engloba 'outras nacionalidades', embora com variações mais amplas, também mantém proporções altas de entradas que se dirigiram ao Estado de São Paulo. Nos períodos de 1920 a 1929 e de 1945 a 1949, o grupo de 'outras nacionalidades' ultrapassa a percentagem de todas as outras nacionalidades específicas que se vem analisando. (ANUÁRIO ESTATÍSTICO DO BRASIL, 1954, p. 49).

Além dos Anuários Estatísticos Brasileiros, é possível encontrar dados sobre o número de imigrantes ingressos e outras variáveis a eles ligadas, em nível nacional, em diversas fontes. Dentre essas estão os relatórios do Ministério dos Negócios do Império (1872-1889), do Departamento Nacional de Imigração e Colonização (DNIC), do Conselho de Imigração e Colonização, da Divisão de Terras e Colonização, do Instituto Nacional de Imigração e Colonização (INIC), da Superintendência de Política Agrária (SUPRA), do Instituto Nacional de Desenvolvimento Agrário (INDA) e do Departamento Nacional de Mão de Obra, Divisão Nacional de Imigração. Já as informações referentes às saídas estariam em mãos do Serviço de Registro de Estrangeiro, pertencente ao Ministério da Justiça. (IBGE, 2003).

A I Guerra Mundial interrompeu sensivelmente a vinda de imigrantes poloneses e de outras origens para o Brasil; ao findar o conflito mundial, o fluxo migratório polonês foi restabelecido, porém em menor escala. No período intitulado "febre brasileira" 1889/1914 - aproximadamente noventa mil poloneses chegaram ao Brasil, dos quais $45 \%$ fixaram-se no Rio Grande do Sul; 40\%, no Paraná e os 15\% restantes em Santa Catarina, São Paulo e Minas Gerais. Em seu estudo pioneiro sobre os poloneses no Rio Grande do Sul, Edmundo Gardolinski apresenta um total de 27 mil imigrantes chegados ao Estado, originando as colônias, até então desocupadas. (GARDOLINSKI, 1958, p. 12)

As estruturas administrativas e políticas do Rio Grande do Sul representavam não somente o fim do escravismo e a implantação do trabalho assalariado, mas também o 
esboço de um projeto de industrialização e de colonização policultora com base na mãode-obra familiar. O positivismo, que na Europa fora a ideologia legitimadora da hegemonia burguesa, no Rio Grande do Sul assumiu noções progressistas em relação ao escravismo anterior e ao domínio do latifúndio charqueador e pecuarista, abrindo espaço para o ingresso da massa imigracional.

Oriundos da região ocupada pela Prússia, os primeiros imigrantes poloneses teriam chegado ao Rio Grande do Sul na segunda metade do século XIX, por volta de 1875. Eles se estabeleceram na margem esquerda do rio das Antas, na Colônia Santa Tereza, que se limitava, ao norte, com a Oitava Seção da Colônia Alfredo Chaves e, ao sul, com a região de colonização alemã. As cidades de Bochnia, Brzesko, Cracóvia, Jarosław, Leżajsk, Przemyśl, Przeworsk, Rzeszów, Sanok, Tarnów, Tarnobrzeg, bem como as que se encontram presentemente nas fronteiras da Ucrânia: Bolechów, Chodorów, Czortków Sambor, Stryj, Stanisławów colaboraram no envio de imigrantes poloneses ao Rio Grande do Sul. (STAWINSKI, 1976, p. 79)

\title{
Espaços de guarda e memórias de Imigrantes poloneses no Rio Grande do Sul
}

Em um mundo onde a globalização e a pós-modernidade incidem sobre as identidades locais, os espaços de memória (Arquivos, galerias e museus) adquirem uma importância para as coletividades em razão de assentar suas pretensões de guarda e ressignificação das memórias individual e coletiva, contribuindo em simultâneo para que essas mesmas identidades possam permitir aos cidadãos refletirem sobre a sua ciclicidade, coletividade, bem como sua cotidianidade. ${ }^{\text {ii }}$

Para Joel Candau,

\begin{abstract}
[...] a memória é acima de tudo uma reconstrução continuamente atualizada do passado, mais do que uma reconstituição do mesmo "a memória é de fato mais um enquadramento do que um conteúdo, um objetivo sempre alcançável, um conjunto de estratégias, um estar aqui que vale menos pelo que é do que pelo que fazemos dele (Pierre Nora). A ideia segundo a qual as experiências passadas seriam memorizadas, conservadas e recuperadas em toda sua integridade parece insustentável” (Suzanne Kuchler) (CANDAU, 2012, p. 9).
\end{abstract}

A memória como passo para a emancipação (NORA, 1999), e identidade (entendida como afirmação social e política) enquanto um princípio organizador preeminente da sociedade (CASTELLS, 2007) constituem forças que impulsionam a 
criação e consolidação da abertura dos espaços como arquivos e museus. Ou seja, os arquivos e os museus atuam como impulsionadores para a inscrição de memórias na paisagem. Tradicionalmente, cabe a estes espaços a reunião, classificação e ordenamento de elementos materiais e intangíveis acerca da ação de sujeitos, comunidades, acontecimentos e instituições.

Nesse contexto, buscou-se demonstrar de forma colaborativa e despretensiosa os espaços (municípios) que possuem locais de guarda e faculdade de conservar e lembrar informações de antepassados na forma de acervos e arquivos públicos e privados no Estado do Rio Grande do Sul. O mapeamento foi realizado entre os anos de 2016 a 2018, como atividade complementar de um estágio Pós-doutoral realizado na Universidade Estadual do Sudoeste do Paraná/UNIOESTE.

\section{Guia da Imigração Polonesa no Sul do Brasil - Rio Grande do Sul}

Tabela 1 - Municípios e Documentos.

\begin{tabular}{|c|c|}
\hline Município & Documento/Série Documentaliii \\
\hline \multirow[t]{2}{*}{ Alegria } & Livros de registro de batizados, óbitos e Tombo \\
\hline & Objetos do cotidiano dos imigrantes \\
\hline Alpestre & Livros de registro de batizados, óbitos e Tombo \\
\hline Antônio Prado & Galeria de Imagens, Livro Tombo \\
\hline \multirow[t]{7}{*}{ Áurea } & Atestados de natalidade e óbitos \\
\hline & Escrituras territoriais \\
\hline & Livros de registro de batizados, óbitos e Tombo \\
\hline & Móveis e utensílios domésticos \\
\hline & Objetos de uso pessoal (Parteira), livros e Revistas \\
\hline & Fotografias, livros e Revistas \\
\hline & Objetos históricos, fotografias, livros e revistas \\
\hline $\begin{array}{l}\text { Campina das } \\
\text { Missões }\end{array}$ & Livros de registro de batizados, óbitos e Tombo \\
\hline \multirow[t]{2}{*}{ Cândido Godói } & Livros de registro de batizados, óbitos e Tombo \\
\hline & $\begin{array}{l}\text { Artefatos, móveis e outros objetos antigos da colonização do município e } \\
\text { também exposição do "Fenômeno dos Gêmeos" }\end{array}$ \\
\hline \multirow[t]{2}{*}{ Carlos Gomes } & Livros de registro de batizados, óbitos e Tombo \\
\hline & Fotografias, livros escritos em polonês, mapas e cartões postais da \\
\hline
\end{tabular}




\begin{tabular}{|c|c|}
\hline & Polônia (Diversas épocas) \\
\hline Casca & Livros de registro de batizados, óbitos e Tombo \\
\hline \multirow[t]{2}{*}{ Centenário } & Livros de registro de batizados, óbitos e Tombo \\
\hline & $\begin{array}{c}\text { Fotografias, livros escritos em polonês, mapas e cartões postais da } \\
\text { Polônia (Diversas épocas) }\end{array}$ \\
\hline Cristal do Sul & Livros de registro de batizados, óbitos e Tombo \\
\hline $\begin{array}{l}\text { Dezesseis de } \\
\text { Novembro }\end{array}$ & Livros de registro de batizados, óbitos e Tombo \\
\hline \multirow[t]{2}{*}{ Dom Feliciano } & Artefatos, móveis e outros objetos antigos da colonização do município \\
\hline & Livros de registro de batizados, óbitos e Tombo \\
\hline \multirow[t]{5}{*}{ Erechim } & Acervo Edmundo Gardolinski \\
\hline & Biblioteca temática (Imigração Polonesa e Poloneses) \\
\hline & $\begin{array}{c}\text { Documentos diversos, passaportes, fotografias e bibliografia (português } \\
\text { x polonês) }\end{array}$ \\
\hline & Fotografia e Livros de Atas. Depoimentos Orais \\
\hline & Objetos pessoais de imigrantes poloneses \\
\hline Ernestina & $\begin{array}{l}\text { Artigos religiosos de forma ecumênica, instrumentos agrícolas e de } \\
\text { trabalho, utensílios domésticos e decoração, peças indígenas e coleções e } \\
\text { fotografias }\end{array}$ \\
\hline Erval Grande & $\begin{array}{l}\text { Artefatos, móveis e outros objetos antigos da colonização do município e } \\
\text { imigrantes }\end{array}$ \\
\hline \multirow{2}{*}{$\begin{array}{c}\text { Frederico } \\
\text { Westphalen }\end{array}$} & Documentos, passaportes, fotografias e bibliografia oficiais \\
\hline & Livros de registro de batizados, óbitos e Tombo \\
\hline \multirow{3}{*}{$\begin{array}{l}\text { Guarani das } \\
\text { Missões }\end{array}$} & Fotografias e depoimentos orais \\
\hline & Objetos do cotidiano e fotografias \\
\hline & Imagens sacras e livro Tombo \\
\hline \multirow[t]{2}{*}{ Gaurama } & Fotografias, Objetos do cotidiano e Passaportes \\
\hline & Livros de registro de batizados, óbitos e Tombo \\
\hline \multirow[t]{2}{*}{ Getúlio Vargas } & Fotografias, documentos públicos municipais, biblioteca \\
\hline & Livros de registro de batizados, óbitos e Tombo \\
\hline \multirow[t]{2}{*}{ Ijuí } & Livros de registro de batizados, óbitos e Tombo \\
\hline & Obras diversas, fotografias e depoimentos orais \\
\hline Mariana Pimentel & Livros de registro de batizados, óbitos e Tombo \\
\hline Nova Prata & Livros de registro de batizados, óbitos e Tombo \\
\hline
\end{tabular}




\begin{tabular}{|c|c|}
\hline & Objetos do cotidiano colonial e fotografias \\
\hline $\begin{array}{l}\text { Palmeira das } \\
\text { Missões }\end{array}$ & $\begin{array}{c}\text { Mapas da ocupação de terras, registro de ingresso de imigrantes } \\
\text { Livros de registro de batizados, óbitos e Tombo }\end{array}$ \\
\hline Planalto & Livros de registro de batizados, óbitos e Tombo \\
\hline Porto Alegre & $\begin{array}{c}\text { Acervo Edmundo Gardolinski/NPH UFRGS } \\
\text { Atas, Lista de Ingressos, fotografias } \\
\text { Biblioteca, Documentos Oficiais das Colônias, Mapoteca, Hemeroteca, } \\
\text { Fotografias diversas } \\
\text { Biblioteca - obras em língua polonesa e português } \\
\text { Fundos Pessoais Privados de Médicos, Práticos e Memorialistas, } \\
\text { depoimentos, fotografias, objetos históricos. Destaque para fontes } \\
\text { referente ao médico polonês Pedro Luiz Napoleão Chernovicz }\end{array}$ \\
\hline Rio Grande & $\begin{array}{l}\text { Atas de Fundação da Sociedade, Livros de Atas que relatam aspectos } \\
\text { socioculturais e desenvolvimento do grupo étnico na cidade e região } \\
\text { Fotografias diversas } \\
\text { Livros de registro de batizados, óbitos e Tombo }\end{array}$ \\
\hline Santa Maria & $\begin{array}{l}\text { Acervo documental da administração pública municipal de Santa } \\
\text { Maria/RS (1868 a 1975) } \\
\text { Acervo iconográfico com imagens que ilustram a história e evolução do } \\
\text { município e região } \\
\text { Acervo bibliográfico: obras de referência sobre Santa Maria/RS e } \\
\text { assuntos em geral } \\
\text { Coleção de jornais local, regional, nacional e internacional (1853 até } \\
\text { nossos dias) } \\
\text { Coleção de moedas nacionais (1938 a 1986) } \\
\text { Coleção de revistas nacionais (1968 até os dias atuais) } \\
\text { Coleção do Instituto Histórico e Geográfico de Santa Maria } \\
\text { Livros de registro de batizados, óbitos e Tombo }\end{array}$ \\
\hline $\begin{array}{l}\text { Santo Antônio da } \\
\text { Patrulha }\end{array}$ & $\begin{array}{c}\text { Documentos públicos, fotografias e jornais relacionados à história do } \\
\text { município e imigrantes. } \\
\text { Livros de registro de batizados, óbitos e Tombo }\end{array}$ \\
\hline São Marcos & $\begin{array}{l}\text { Peças Sacras, fotografias e quadros. Biblioteca. } \\
\text { Livros de registro de batizados, casamentos, óbitos e Tombo }\end{array}$ \\
\hline
\end{tabular}

Fonte: Elaborada pela autora (2020).

Tabela 2 - Acervo, localização e acessibilidade.

\begin{tabular}{|c|c|c|}
\hline Município/Acervo & Acessibilidade & Outras Informações \\
\hline
\end{tabular}




\begin{tabular}{|c|c|c|}
\hline $\begin{array}{c}\text { Alegria/Paróquia São Sebastião } \\
\text { Museu Municipal }\end{array}$ & $\begin{array}{l}\text { Exige agendamento } \\
\text { Livre acesso }\end{array}$ & $\begin{array}{c}\text { Em catalogação } \\
\text { Catalogação parcial }\end{array}$ \\
\hline $\begin{array}{l}\text { Alpestre/Paróquia São Francisco de } \\
\text { Assis }\end{array}$ & Exige agendamento & Sem catalogação \\
\hline $\begin{array}{l}\text { Antônio Prado /Paróquia Sagrado } \\
\text { Coração de Jesus }\end{array}$ & Exige agendamento & $\begin{array}{l}\text { Acervo catalogado e em } \\
\text { bom estado de } \\
\text { conservação }\end{array}$ \\
\hline $\begin{array}{l}\text { Áurea/Cartório de Registros Notariais e } \\
\text { de Serviços }\end{array}$ & $\begin{array}{l}\text { Exige liberação } \\
\text { Exige liberação }\end{array}$ & $\begin{array}{lrr}\text { Acervo catalogado er em } \\
\text { bom } & \text { estado } & \text { de } \\
\text { conservação. Documentos } \\
\text { dos séculos XIX e XX }\end{array}$ \\
\hline Paróquia Nossa Senhora do Monte Claro & Livre acesso & $\begin{array}{l}\text { Acervo em bom estado de } \\
\text { conservação }\end{array}$ \\
\hline Arquivo particular de Maria Volt & & Não catalogado \\
\hline & Livre acesso & \\
\hline $\begin{array}{l}\text { Arquivo particular de Gema Precheski } \\
\text { Museu Municipal João Modtkowski }\end{array}$ & Livre acesso & $\begin{array}{l}\text { Parcialmente catalogado. } \\
\text { Documentos dos séculos } \\
\text { XIX e XX }\end{array}$ \\
\hline Casa do Imigrante Família Popoawski & Livre acesso & $\begin{array}{l}\text { Acervo catalogado e em } \\
\text { bom estado de conservação }\end{array}$ \\
\hline $\begin{array}{c}\text { Campina das Missões /Igreja Matriz } \\
\text { Campina das Missões }\end{array}$ & Exige liberação & Não catalogado \\
\hline $\begin{array}{c}\text { Cândido Godói /Igreja Matriz Cândido } \\
\text { Godói } \\
\text { Museu Histórico Municipal }\end{array}$ & $\begin{array}{l}\text { Exige liberação } \\
\text { Livre acesso }\end{array}$ & 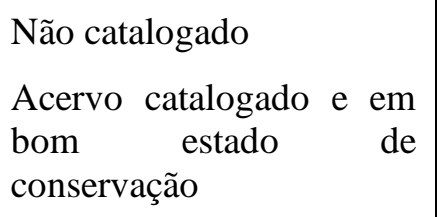 \\
\hline $\begin{array}{c}\text { Carlos Gomes/Igreja Matriz Sant’Ana } \\
\text { Família Gorski }\end{array}$ & $\begin{array}{l}\text { Exige liberação } \\
\text { Livre acesso }\end{array}$ & $\begin{array}{l}\text { Não catalogado } \\
\text { Catalogado }\end{array}$ \\
\hline Casca/Paróquia São Luiz Gonzaga & Exige liberação & Não catalogado \\
\hline Centenário/Paróquia André Bobola & Exige liberação & Não catalogado \\
\hline $\begin{array}{l}\text { Cristal do Sul/Capela Nossa Senhora } \\
\text { Imaculada Conceição }\end{array}$ & Exige liberação & Não catalogado \\
\hline Dezesseis de Novembro /Igreja Matriz & Exige liberação & Não catalogado \\
\hline $\begin{array}{c}\text { Dom Feliciano /Casa da Cultura e } \\
\text { Museu Municipal } \\
\text { Paróquia de Nossa Senhora de } \\
\text { Czestochowa }\end{array}$ & $\begin{array}{l}\text { Livre Acesso } \\
\text { Exige liberação }\end{array}$ & $\begin{array}{l}\text { Acervo catalogado e em } \\
\text { bom estado } \\
\text { conservação } \\
\text { Acervo catalogado e } \\
\text { bom em } \\
\text { bom estado }\end{array}$ \\
\hline
\end{tabular}




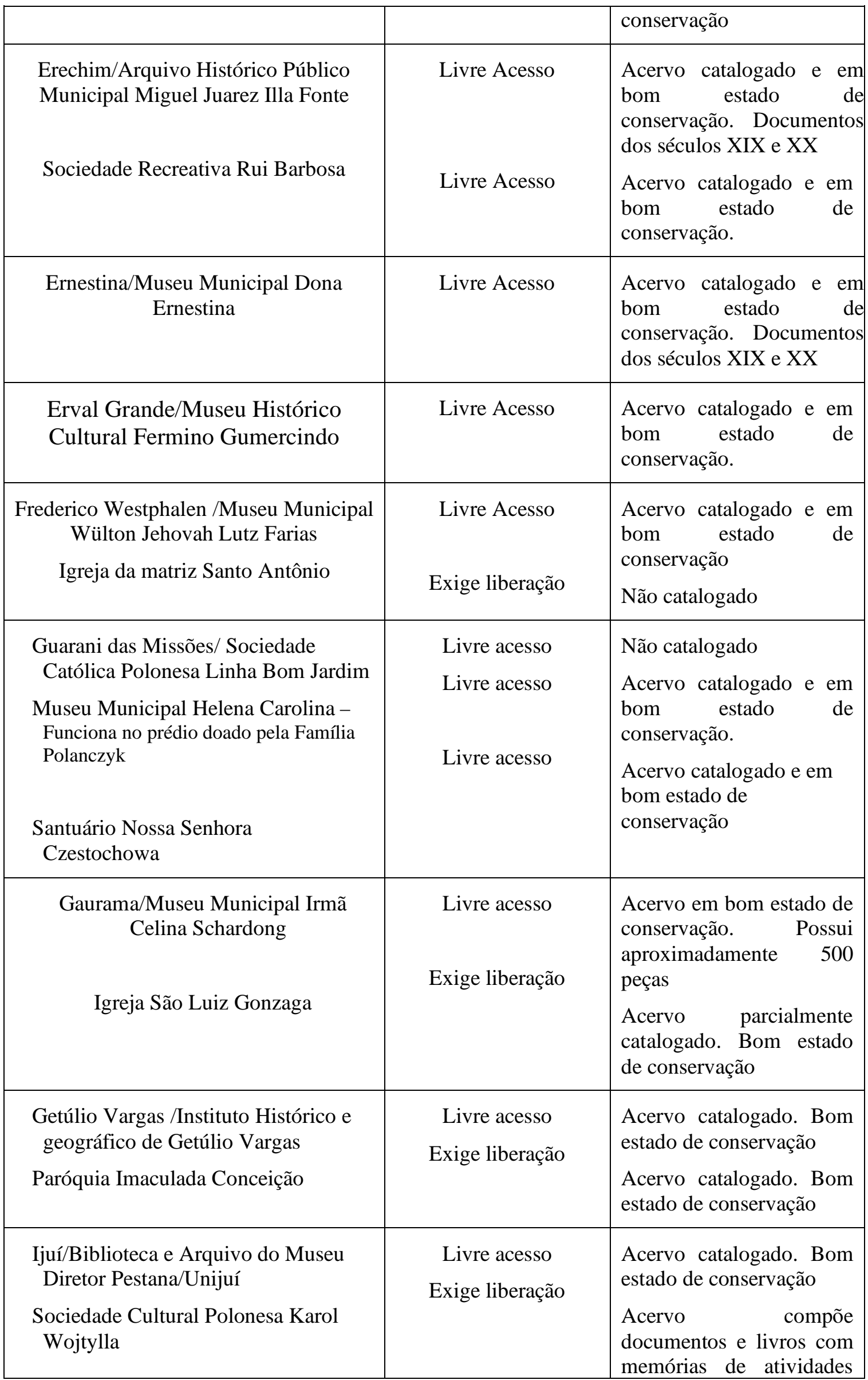




\begin{tabular}{|c|c|c|}
\hline & & culturais. \\
\hline $\begin{array}{l}\text { Mariana Pimentel/Paróquia Nossa } \\
\text { Senhora do Rosário }\end{array}$ & Exige Liberação & Não catalogado \\
\hline $\begin{array}{l}\text { Nova Prata/Igreja Matriz São João } \\
\text { Batista } \\
\text { Museu Municipal Domingos Batisttel }\end{array}$ & $\begin{array}{l}\text { Exige liberação } \\
\text { Livre Acesso }\end{array}$ & $\begin{array}{l}\text { Não catalogado } \\
\text { Acervo catalogado. Bom } \\
\text { estado de conservação }\end{array}$ \\
\hline $\begin{array}{l}\text { Palmeira das Missões /Museu } \\
\text { Municipal Dr. Dorvalino Luciano de } \\
\text { Souza }\end{array}$ & Livre Acesso & $\begin{array}{l}\text { Acervo catalogado er em } \\
\text { razoável estado r de } \\
\text { conservação. Documentos } \\
\text { dos séculos XIX e XX }\end{array}$ \\
\hline $\begin{array}{l}\text { Planalto/Paróquia Nossa Senhora das } \\
\text { Graças }\end{array}$ & Exige liberação & $\begin{array}{l}\text { Parte do Acervo encontra- } \\
\text { se na Mitra de Frederico } \\
\text { Westphalen }\end{array}$ \\
\hline $\begin{array}{l}\text { Porto Alegre/Arquivo Histórico do Rio } \\
\text { Grande do Sul } \\
\text { Instituto Histórico e Geográfico }\end{array}$ & $\begin{array}{l}\text { Exige Liberação } \\
\text { Exige Liberação }\end{array}$ & $\begin{array}{l}\text { Acervo catalogado er em } \\
\text { bom estado } r \text { de } \\
\text { conservação. Documentos } \\
\text { dos séculos XVIII, XIX e } \\
\text { XX }\end{array}$ \\
\hline Sociedade Polônia de Porto Alegre & Exige Liberação & $\begin{array}{l}\text { Acervo catalogado e em } \\
\text { bom estado de conservação }\end{array}$ \\
\hline \multirow[t]{2}{*}{ Museu de História da Medicina } & Livre Acesso & $\begin{array}{l}\text { Acervo com grande } \\
\text { quantidade de obras }-5000 \\
\text { exemplares. Bom estado de } \\
\text { conservação }\end{array}$ \\
\hline & Livre Acesso & $\begin{array}{l}\text { Acervo com grande } \\
\text { quantidade de obras. Bom } \\
\text { estado de conservação e } \\
\text { catalogado }\end{array}$ \\
\hline $\begin{array}{c}\text { Rio Grande/Sociedade Cultural Águia } \\
\text { Branca - Towarzystwo Kulturalne Orzel } \\
\text { Bialy }\end{array}$ & Livre Acesso & $\begin{array}{l}\text { Acervo em bom estado de } \\
\text { conservação. O prédio da } \\
\text { Sociedade Águia Branca } \\
\text { compõe um dos espaços de } \\
\text { memória arquitetônica da } \\
\text { metade Sul }\end{array}$ \\
\hline $\begin{array}{c}\text { Santa Maria/Museu Municipal Santa } \\
\text { Maria }\end{array}$ & Livre Acesso & $\begin{array}{l}\text { Acervo catalogado e em } \\
\text { bom estado de } \\
\text { conservação. Possui mais } \\
\text { de } 100.000 \text { documentos } \\
\text { no total e em torno de } \\
10 \% \text { correspondente a } \\
\text { imigração }\end{array}$ \\
\hline $\begin{array}{l}\text { Santo Antônio da Patrulha /Fundação } \\
\text { Museu Antropológico Caldas Júnior }\end{array}$ & Livre acesso & $\begin{array}{l}\text { Acervo em bom estado de } \\
\text { conservação e catalogado }\end{array}$ \\
\hline
\end{tabular}




\begin{tabular}{|c|c|c|}
\hline & & parcialmente \\
\hline $\begin{array}{c}\text { São Marcos/ Museu Paroquial } \\
\text { Paróquia de São Marcos }\end{array}$ & $\begin{array}{c}\text { Livre acesso } \\
\text { Exige liberação }\end{array}$ & $\begin{array}{l}\text { Acervo catalogado e bom } \\
\text { estado de conservação. É } \\
\text { um dos pontos turísticos } \\
\text { da cidade } \\
\text { Acervo catalogado e em } \\
\text { bom estado de } \\
\text { conservação e não } \\
\text { catalogado }\end{array}$ \\
\hline
\end{tabular}

Fonte: Elaborada pela autora (2020).

Insta destacar que grande parte dos municípios assentam seus acervos nos registros da Igreja Cristã Católica. O Patrimônio Documental da Igreja inclui à documentação iconográfica (por exemplo, pode-se citar a Paróquia de Áurea, Gaurama e Guarani das Missões) e, audiovisual, multimeios. Essa prevalência da Igreja registrar grande parte da história dos cidadãos é devido sua historicidade (tradição milenar de dominação) e por ter maior e melhor estrutura para realizar os registros de grande parte da população.

Em sua maioria, a instituição Igreja reconhece a importância da documentação por ela produzida, principalmente a documentação das dioceses e paróquias, de acordo com o Direito Canônico, normatizando que a documentação seja custodiada com diligência e responsabilidade. O atual Código de Direito Canônico, promulgado em 1983, no cânon 535 parágrafos de $1^{\circ}$ ao $5^{\circ}$, dispõe da seguinte maneira acerca dos livros paroquiais:

$\S 1$ - E cada paróquia, haja os livros paroquiais, isto é, o livro de batizados, de casamentos, de óbitos, e outros, de acordo com as prescrições da Conferência dos Bispos ou do Bispo Diocesano; cuide o pároco que esses livros sejam cuidadosamente escritos e diligentemente guardados.

$\S 2$ - No livro de batizados seja anotada também a confirmação, como ainda o que se refere ao estado canônico dos fiéis, por motivo de matrimônio, salva a prescrição do cân. 1133, por motivo de adoção, de ordem sacra recebida, de profissão perpétua emitida em instituto religioso e de mudança de rito; essas anotações sejam sempre referidas na certidão de batismo.

$\S 3$ - Cada paróquia tenha o próprio selo; as certidões que se dão a respeito do estado canônico dos fiéis, como também os atos que podem ter valor jurídico, sejam assinados pelo pároco ou por seu delegado e munidos com o selo da paróquia.

$\S 4$ - Em cada paróquia haja um cartório ou arquivo, em que se guardem os livros paroquiais, juntamente com as cartas dos Bispos e outros que devem ser conservados por necessidade ou utilidade; tudo isso, que deverá ser examinado pelo Bispo Diocesano ou seu delegado na visita canônica ou em outro tempo oportuno, o pároco cuide que não chegue a mãos de estranhos.

$\S 5$ - Também os livros paroquiais mais antigos, sejam guardados diligentemente, de acordo com as prescrições do direito particular. (FONTES, 2000)

No tocante aos Acervos e Arquivos Particulares foi possível mapear que em 
cidades com 300 mil ou mais habitantes como é o caso de Caxias do Sul, Canoas, Pelotas e Porto Alegre, há diversos acervos e arquivos particulares, porém não foi possível registrar detalhadamente por questões de acesso e tempo empreendido para a pesquisa. Como exemplo, destaca-se o Acervo particular da família Gardolinski ${ }^{\text {iv }}$ - residente em Porto Alegre. A família Gardolinski realizou duas doações para Instituições Públicas no século XX: Erechim e Porto Alegre.

Na cidade de Porto Alegre a doação foi para o Núcleo de Pesquisa em História e foi denominado de Fundo Edmundo Gardolinski. O acervo foi doado à UFRGS pela família do titular, após o seu falecimento, em 1974. A documentação permaneceu inacessível à consulta durante vários anos, até sua organização na década de 1980, que contou com o auxílio da Fundação de Amparo à Pesquisa do Estado do Rio Grande do Sul (FAPERGS).

A parte documental do Fundo Edmundo Gardolinski é constituída de documentos de vários tipos: rascunhos anotados e corrigidos de artigos e discursos do titular e de outros autores, correspondências, folhetos, prospectos, recortes de jornais e revistas (em número aproximado de 1500), e outros documentos, além da biblioteca do titular, que contém periódicos, livros e folhetos. Este material foi organizado em sete séries, de acordo com as atividades de Gardolinski, o tipo de documento e o assunto: Imigração, Polônia, Documentação Pessoal, Frederic Chopin, Nicolau Copérnico e Orquídeas. (UFRGS/ACERVO GARDOLINSKI, 2019)

O acervo fotográfico compõe-se de imagens relativas à construção da Vila do IAPI e à imigração polonesa para o Rio Grande do Sul. O conjunto de fotografias sobre a presença da etnia polonesa no Brasil - que representam diversos temas, como festas familiares e religiosas, cotidiano agrário e pequeno comércio de cidades do interior do Rio do Rio Grande do Sul - foi identificado e organizado com a contribuição de membros da comunidade de descendentes de imigrantes ao longo de vários anos. As quase três centenas de imagens identificadas e catalogadas foram produzidas entre o final do século XIX e década de 1960, sendo a maioria do período de 1920 a 1940. Parte deste material foi posteriormente digitalizado e encontra-se disponível para reprodução. ${ }^{\mathrm{V}}$ (UFRGS/ACERVO GARDOLINSKI, 2019).

O Acervo Edmundo Gardolinski existente junto ao Arquivo Público Municipal Juarez Miguel Illa Font possui brochuras, depoimento oral, fotografias, livros, plantas arquitetônicas e Revistas. Este arquivo foi fundado no ano de 1980 com apoio de professores e pesquisadores locais e dez anos após, passou a denominar-se Arquivo 
Histórico Municipal Juarez Miguel Illa Font (AHM). Suas principais funções e atribuições são: dar busca, guarda e conservação da documentação histórica do município e região ao Alto Uruguai, bem como permitir a utilização de seu acervo para consulta ao público em geral. Desta forma, o seu acervo documental constitui um patrimônio documental de imensurável valor histórico/cultural para o município e região. Dentre este patrimônio, inclui-se um acervo fotográfico e o destaque para inúmeras pastas de documentos oficiais sobre a imigração polonesa nas Colônias novas e um significativo número de fotografias (mais de três centenas).

Em 2014 a família Gardolinski, representada por André e Edmundo Gardolinski Filho realizaram outra doação para o Arquivo Público Municipal Juarez Miguel Illa Font localizado na cidade de Erechim. Foram doados cartazes temáticos (Centenário da Imigração Polonesa no Brasil), cartões postais, croquis, desenhos, livros e fotografias. A doação foi rapidamente catalogada e disponibilizada para pesquisadores. O acesso foi liberado para consulta e uso do material em trinta dias após a doação.

Já as cidades de Alvorada, Gravataí, Novo Hamburgo, Santa Maria, São Leopoldo e Viamão que têm 200 mil ou mais habitantes, há diversos Arquivos Particulares os quais não foram possíveis de mapear, bem como algumas cidades que possuem 100 mil ou mais habitantes como Bagé, Bento Gonçalves, Cachoeirinha, Passo Fundo, Rio Grande, Santa Cruz do Sul e Uruguaiana por questões de logística, entretanto todas possuem pequenas comunidades de imigrantes ou descendentes de poloneses o que indica a possibilidade da presença de espaços de guarda de memória.

\section{Conclusão}

A articulação entre a cultura, as identidades e a memória nos grupos de imigrantes poloneses caracterizam-se pelo movimento de ressignificações sociais após o processo de deslocamento de suas memórias na condição de homem do novo mundo. O que inicialmente marcou suas trajetórias foi o plantar, colher, tornar-se um pequeno proprietário e, com o passar do tempo sendo ampliado para suas subjetivações coletivas.

Muitos grupos e municípios vão reforçar essa identidade, selecionada a partir de ações estruturadas por interesses locais, não só no sentido de guarda e preservação, mas no sentido de legitimação cultural. Com relação a esse último aspecto, tem-se o papel de grupos específicos que se colocam como agentes que acabam por institucionalizar a 
memória local a partir de escolhas que nem sempre representam o pertencimento cultural da maioria. Para validar essa compreensão, sabe-se que as materializações culturais (tais como as expressões arquitetônicas, as festividades, a gastronomia e mesmo a religiosidade) que apresentam traços/características reconhecidos como sendo manifestações da cultura polonesa - dos antepassados vindos da Polônia e/ou de seus descendentes - são identificados e tornados públicos, isto é, passam a ser divulgados e, por vezes, até explorados promocionalmente.

À guisa de conclusão, pode-se dizer, por meio da análise e entrelaçamentos dos dados coletados durante o processo da pesquisa empírica que as Congregações Religiosas e as Igrejas são as guardiãs dos espaços de guarda e preservação das trajetórias históricas do grupo em tela. As informações contidas nos Livros Paroquiais seguem três níveis de descrição: nome e numeração nos Livros (em ordem crescente); uso dos números arábicos; nome, ano e localização no livro - com base na catalogação desenvolvida pela Mitra e nome, data completa e localização do livro - seguido de pequeno índice em caderneta avulsa.

Grande parte das pesquisas realizadas na atualidade se dá em razão de pedidos dos fiéis a fim de comprovar endereço, idade, ou outras necessidades legais. Essa pesquisa é realizada pelo pároco ou funcionário da Secretaria Canônica. Demais pesquisadores somente sob autorização do responsável pelo Arquivo e Patrimônio da Igreja ou Mitra. A pesquisa nos registros paroquiais pode ser feita, considerando: apenas um nome (homem ou mulher); os dois nomes de um casal pretendido (casamentos) e um nome, de homem ou mulher, e os dos pais (ou só pai/só mãe), no caso de se tratar do livro de batismo ou data em que se deu o ritual religioso. No tocante aos nomes e sobrenomes de imigrantes poloneses em alguns casos sofreram alteração da grafia trazida no passaporte.

Os espaços denominados museus são ecléticos. Possuem desde recortes de jornais a utensílios domésticos e de trabalho de alguma época. Não raro as municipalidades utilizam-se dos espaços de memória para estimular a atividade turística ou logomatizar as identidades e dessa forma, produzem releituras contemporâneas que se aproximam muito mais de uma etnicidade customizada para instituir e dar justificativa para o aproveitamento das questões étnico-culturais, identitárias e de memória do que permitir que as identidades locais possuam abrigo para desenvolver seus pertencimentos. 


\section{Referências}

BRASIL. IBGE. Anuário Estatístico do Brasil. Rio de Janerio: Imprensa Oficial, 1954.

CANDAU, Joel. Memória e Identidade. Tradução de Maria Letícia Ferreira. São Paulo: Contexto, 2012.

CASTELLS, Manuel. A sociedade em rede. A era da informação: economia, sociedade e cultura. Tradução de Roneide Venancio Majer. Atualização: Jussara Simões. v. 1, 10. ed. São Paulo: Paz e Terra, 2007.

FONTES, Paulo F.O.; ROSA, Ma . de Lurdes. Arquivística e arquivos religiosos: Contributos para uma reflexão. Centro de Estudos de História Religiosa/Universidade Católica Portuguesa: Lisboa, 2000.

GARDOLINSKI, Edmundo. Imigração e colonização polonesa. In: BECKER, Klaus (org.). Enciclopédia riograndense. Porto Alegre: Regional, 1958.

GARDOLINSKI, Edmundo. In: Anuário Brasileiro de Imigração e Colonização. 1961.

INSTITUTO BRASILEIRO DE GEOGRAFIA E ESTATÍSTICA. Estatísticas do século XX. Centro de documentação e disseminação de informações. Rio de Janeiro: IBGE, 2003.

NORA, Pierre (1999). Memory and collective identity. Paper presented at the conference "The future of the past - Remembering and forgetting on the threshold of the new millennium". Disponível em: http://www.hquandtstiftung.de/root/index.php?lang=de\&page_id=448. Last. Acesso em: 08 jun. 2020.

PREFEITURA MUNICIPAL DE ERECHIM. Arquivo Público Municipal Juarez Illa Font. Acervo Gardolinski. Erechim, 2020.

SMOLANA, Krzysztol; DEMBICZ, Andrej. A presença polonesa na América Latina. Roteiros Poloneses na América Latina. CESLA: Centro de Estudos Latino-Americanos. Varsóvia: Universidade de Varsóvia, 1996.

STAWINSKI, Alberto Victor. Primórdios da imigração polonesa no Rio Grande do Sul. Caxias do Sul. UCS. Porto Alegre: EST, 1976.

UNIVERSIDADE FEDERAL DO RIO GRANDE DO SUL. Núcleo de Pesquisa em História. Acervo Gardolinki. Porto Alegre: IFCH, 2019. Disponível em: https://www.ufrgs.br/nph/acervo/fundo-arquivo-edmundo-gardolinski/. Acesso em: 13 jun. 2020.

WACHOWICZ, Ruy Chistovam. O camponês polonês - raízes medievais na mentalidade emergente. 1974. Tese (Concurso à Docência Livre. Disciplina de História Medieval). Universidade Federal do Paraná, Curitiba, 1974.

WEBER, Roswithia. Mosaico identitário: história, identidade e turismo nos municípios da Rota Romântica-RS. 2006. Tese (Doutorado em História). Universidade Federal do Rio Grande do Sul. Porto Alegre, 2006. 
Submetido em: 17/01/2020

Aprovado em: 08/09/2020

Publicado: 23/09/2020

\begin{abstract}
${ }^{\text {i }}$ Docente adjunta/pesquisador sênior da Universidade Estadual do Rio Grande do Sul/UERGS. Professora Titular no Programa de Pós-Graduação Stricto Sensu em Direito/UNOESC. Professora Colaboradora no Programa de Pós-graduação Stricto Sensu em Educação da Universidade Estadual do Paraná- UNIOESTE.

ii Para essa temática recomenda-se Cook, Terry e Schwartz, Joan M, "Arquivos, Documentos e Poder: a construção da memória moderna", In: Revista do Arquivo Público Municipal de Indaiatuba: Fundação PróMemória de Indaiatuba, São Paulo, 2004 e Derrida, Jacques, "Mal de arquivo: uma impressão freudiana", Rio de Janeiro: Relume-Dumará, 2001.

iii Optou-se por manter a terminologia utilizada pelos lugares de memória para garantir a originalidade da pesquisa. Ou seja, cada Arquivo, Museu e outros possui uma metodologia própria de registro e essa não foi alterada no registro desse estudo em reconhecimento à autonomia dos gestores. Grande parte dos municípios não possui um arqueólogo, arquivologista, historiador ou biblioteconomista para realizar a catalogação das peças ou gerenciamento do registro. Em grande parte dos organismos acumuladores/ produtores de arquivos, é pouco frequente que a organização dos documentos esteja a cargo de um profissional e até voluntário que conheça e aplique ao seu trabalho os princípios técnicos arquivísticos.

iv Edmundo Gardolinski nasceu no Estado do Paraná, em 1914, filho de imigrantes poloneses, e veio ao Rio Grande do Sul em 1941, como engenheiro responsável pela construção da Vila operária do IAPI, em Porto Alegre. Dedicou-se ao estudo da história da colonização e imigração polonesa, visitando pessoalmente os núcleos de imigrantes poloneses no Rio Grande do Sul e outros estados, realizando entrevistas, pesquisando e coletando a documentação local. Foi autor de inúmeros artigos, publicados no Brasil e no exterior.
\end{abstract}

$\checkmark$ A equipe responsável pela organização do acervo foi composta pela Professora Regina Weber (Departamento de História e Programa de Pós-Graduação em História - UFRGS) e os pesquisadores do NPH Francisco Carvalho Junior (organização das fotos) e Lizete Oliveira Kummer. Participaram em diversas etapas do trabalho os bolsistas de graduação: Anna Katarzyna Kopaczewska, Érico Pinheiro Fernandez, Márcia Janete Espig e Viviane Carrion Castanho. 